\title{
Evaluation of options for strengthening weak bases of embankments of transport infrastructure facilities
}

\author{
Alexander Shteyn ${ }^{1}$, Andrey Zaytsev ${ }^{1,}{ }^{*}$, Alexander Cherkasov $^{1}$, Alexander Cherbakov ${ }^{2}$, and \\ Sergey Philipov ${ }^{2}$ \\ ${ }^{1}$ Russian University of Transport, 9 b9 Obrazcova St., Moscow, 127994, Russia \\ ${ }^{2}$ JSC GEOHIM, 7 Bolshoy Strochenovsky per., 115054, Russia
}

\begin{abstract}
The rise in highway design and construction requires ensuring the reliability of these infrastructure projects. This is especially important for construction on weak soils. The number of design solutions is equally on the rise for reinforcing the grounds of soil transport structures. Examples include the use of various types of piles, and structures made of sand, gravel and other draining soils placed in a shell of geosynthetic material. The article presents the results of the authors' work on the substantiation and implementation of various constructive solutions to strengthen the insufficiently strong bases on railway and highway construction facilities (railway lines Losevo-Kamennogorsk, MoscowKazan high-speed railroad, Moscow-Saint Petersburg high-speed highway, etc.).
\end{abstract}

\section{Introduction}

It is necessary to perform several computations to evaluate the effectiveness of constructive and technological solutions and choose the right method of strengthening the roadbed basis of transport infrastructure facilities.

These computations include:

1. Computations of the stress-strain state of the structure - These computations help determine the compliance of constructive and technological solutions to the requirements of current regulations and specification parameters.

2. Technical and commercials calculations that determine the capital and operating costs of the implementation of the comparable constructive and technological solutions.

The present article is devoted to the analysis based on the first type of computations.

Today on the operating Russian railways and highways, the application of rigid concrete, ferroconcrete or timber piles is the main method of subgrade reinforcing of embankments. One example of embankment reinforcing by ferroconcrete piles is enclosure structures as presented on Fig. 1. The method of reinforcing embankments on marshes and peat foundation with wooden piles is useful and allowed to reinforce more than 30 kilometers on the railway line in Arkhangelsk district [1,2].

* Corresponding author: andrei.zaitsev2010@yandex.ru 
The embankment strengthening was achieved through applying pulse discharge technology, using berms and timber pile grating consistently with four, three and two piles. This technology uses different kinds of piles, and in additional to economic constraints, has some other disadvantages, notably problems of corrosion and putrefaction. These circumstances led to a search for other types of soil strengthening and prevention of subgrade deformations.

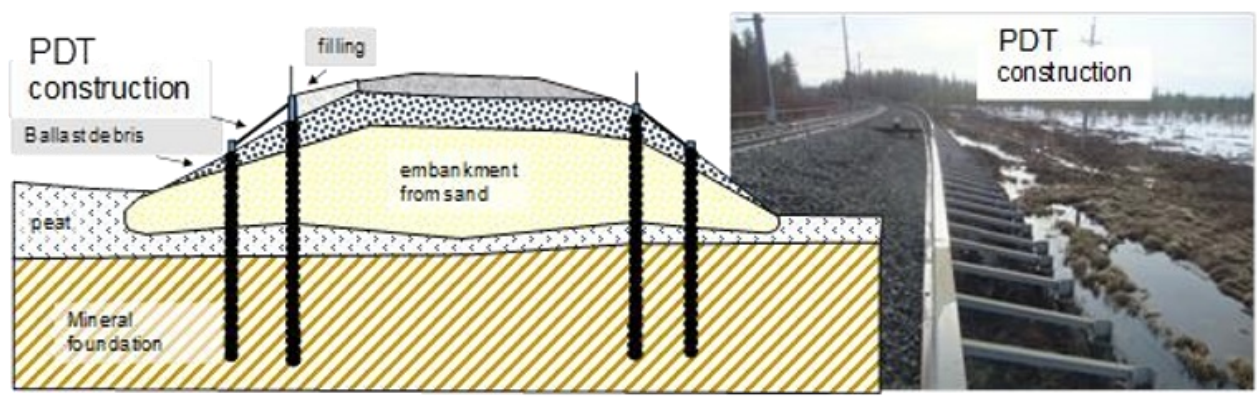

Fig. 1. Embankment reinforced with pulse discharge technology.

The method of soil strengthening with sand piles was first introduced on the railways in North America in the late 40s of the twentieth century and has become widespread on the American and Canadian railways, as well as on the roads of India, Japan and many other countries. In 1970s this method was used in Russia in the construction of the St. Petersburg-Murmansk highway. In that instance, the sand piles were set without geotextile shell.

\section{Evaluation of options for strengthening the subgrade in the facilities of the railway line Losevo-Kamenogorsk and Sankt- Petersburg highway}

\subsection{Description of construction requirements}

The construction of the line was driven by the need to organize high-speed services from St. Petersburg (Russia) to Helsinki (Finland). The objective was to increase the speed up to $200 \mathrm{~km} / \mathrm{h}$ across the entire railway line, allowing to cover the distance in 3.5 hours. In this case, freight services with Finland and two ports (including passenger) with about 30-40 train-pairs seriously complicated the construction efforts.

The total length of the line is about $62 \mathrm{~km}$, and approximately nine kilometers of the embankment are laid on marshy lands and areas with weak soils where customised design solutions had to be applied [1]. During the design and construction of the high-speed Moscow-St. Petersburg highway, measures were also taken to strengthen the embankments on weak soils. The designers of high-speed railroad Moscow-Kazan met the same problems in the process of designing roadbed on weak subgrade that is not robust enough [3].

\subsection{Solutions for the construction of embankments on weak soils}

Piles of sand or gravel in geotextile shells can be used to increase the load bearing capacity of subgrade weak soils. A special advantage of these piles is the supporting effect of shell in weak soils, i.e., peat, silt or clay soils having soft or fluid-like consistency. The shell 
performs not only a reinforcing function, but it also provides the filtration stability between the filling of the piles and the surrounding soil.

The piles need to be arranged in a certain order. As a rule, a triangular or rectangular layout is used. The shells of geotextile are produced using woven geotextile, geogrids or geocomposite materials. The shell is adjusted according to the diameter of embedded pile according to the embedding technology. It covers the entire length of the well in weak layers of soils. A horizontal layer of geogrid should be placed over the upper parts of any piles, to provide stability of the soil and to respond to horizontal and shear stresses.

There are two main installation methods of piles with geotextile shell [4]: excavation and soil displacement.

In the method of displacement, deep vibro techniques for creation of stone / sand / gravel column piles with geotextile shell are used. The filling of the pile shell is carried out using materials (sand/gravel) during the compaction process by the depth vibrator.

The method of excavation is preferable on the soils with high resistance to vibration or if there are requirements to minimize the vibration effect on nearby buildings or transport facilities. Figure 2 is a schematic representation of the reinforcement of the embankment subgrade with piles in a geotextile shell.

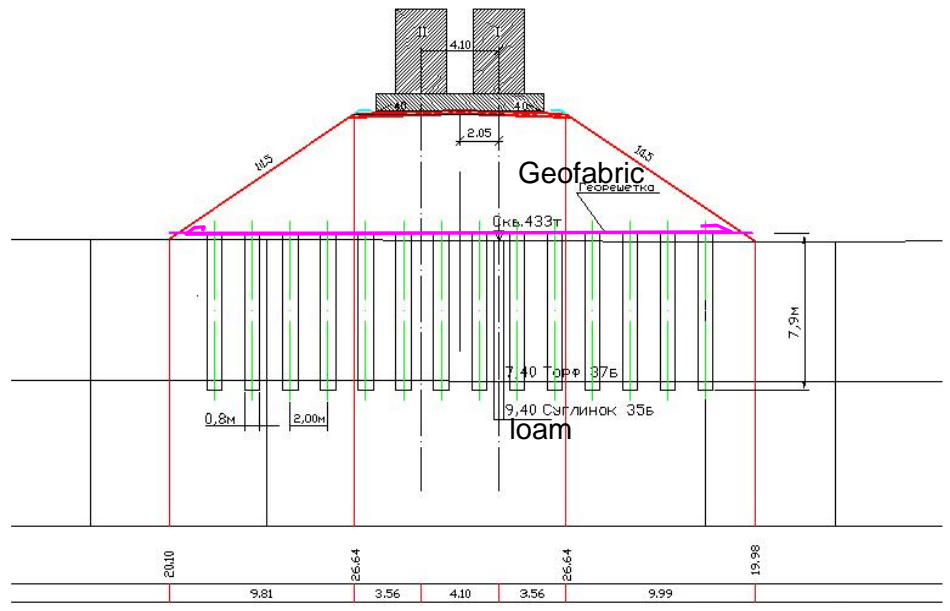

Fig. 2. The cross section of embankment (height $7 \mathrm{~m}$ ) on peat foundation with a sand column.

Fig. 3 shows the change in stability factor in two cases. The first case is not strengthened base soils; the second is for base soils strengthened by piles from sand or gravel in geotextile shells.
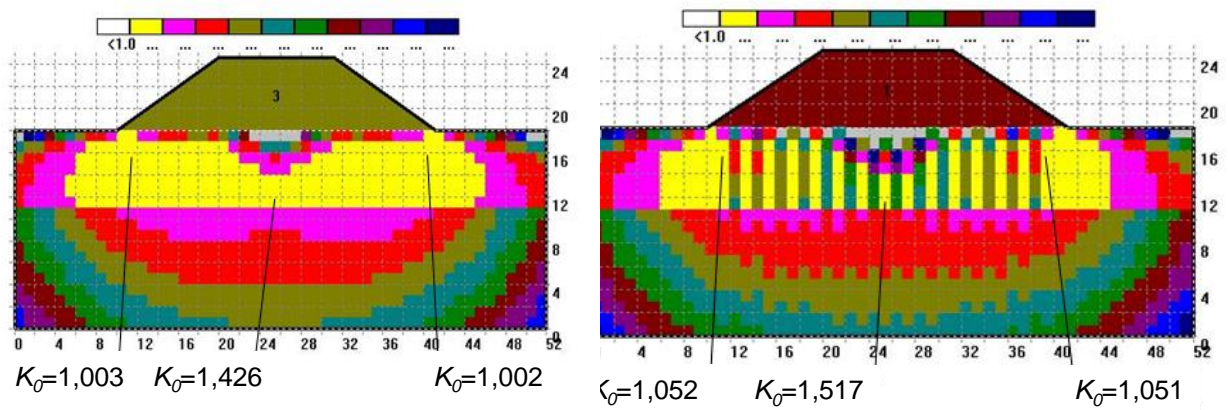

Fig. 3. The estimation of the Shahunyants stability factor (UFOS software). 


\section{The FEM modelling of the highway embankment on weak foundation}

As an example, a highway embankment of twelve meters high was considered. The embankment is designed on the base of soft-plastic and stiff-plastic consistency formed by loams. Also in this base, at the depth of about 8-9 meters, lies a layer of buried peat with a thickness of 2.5-3 meters. The peat was drained and compacted to a medium degree of decomposition. Peat moisture was up to $150 \%$.

The presence of a layer of buried peat imposes certain limitations on the options for constructive and technological solutions. For example, we don't consider the option of strengthening the structure with berms. Berms would increase the stresses in the base and result in the overall deformation of construction.

The temporary load is accepted 18A in accordance with [5]. It is assumed that the carriageway consists of six lanes. Since the computations are methodical in nature, this load was applied to both stability computations and settlement computations. The basic physical and mechanical properties of the base and embankment soils, as well as other structural materials, are provided in Table 1.

Table 1. Basic physical and mechanical parameters of soils, as well as other structural materials.

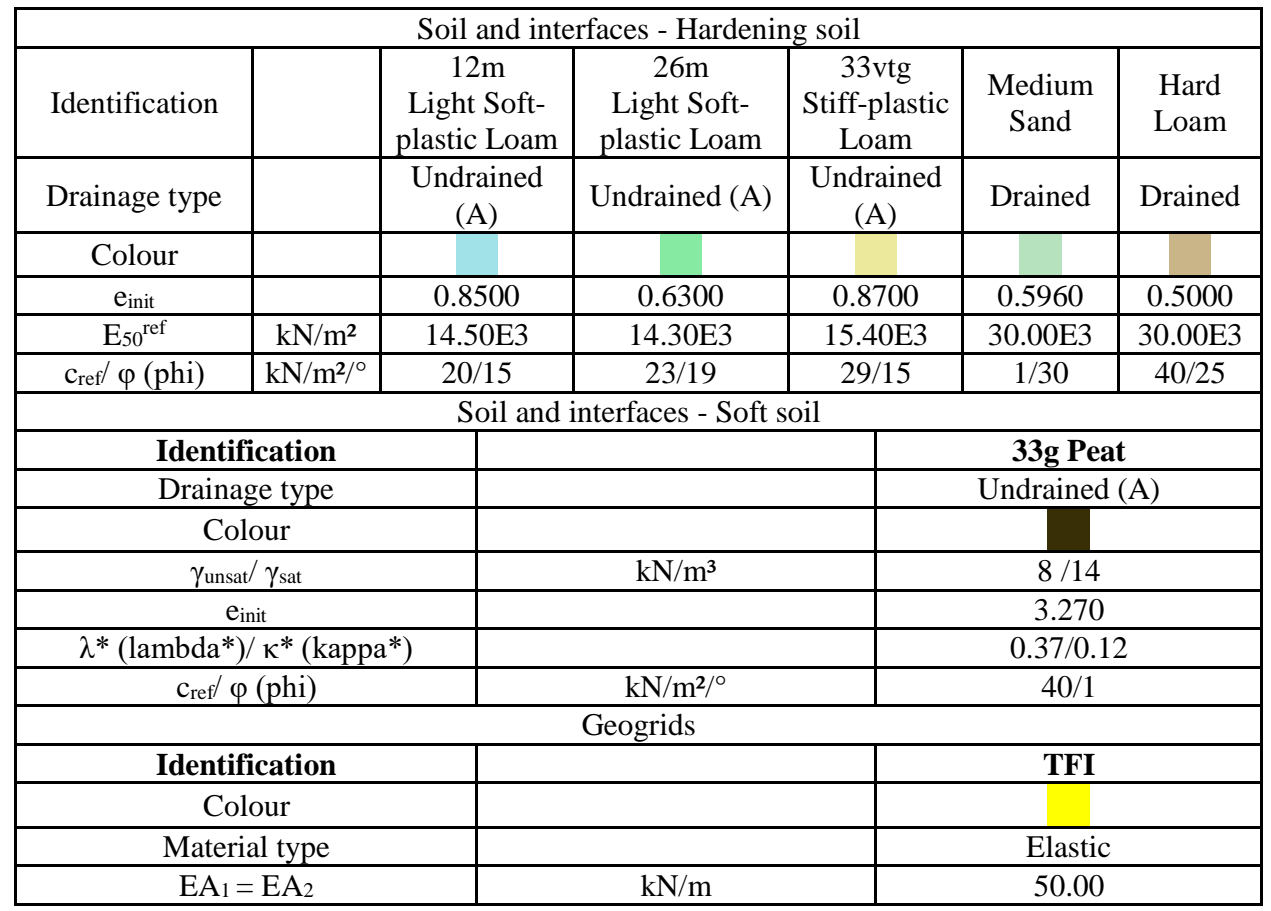

The methods for determining the properties of soils under the influence of climatic factors are described in the manual [6] and their change in the construction period in the article [7].

In total, five options of the embankment design on a weak base were considered. Computations were carried out using the software complex Plaxis 2D. In the computations it is assumed that the embankment will be constructed in four stages. First, a layer of thickness up to two meters is constructed. Then, the layers of $4 \mathrm{~m}$ thick, $4.7 \mathrm{~m}$ thick and a road pavement of $1.3 \mathrm{~m}$ thick. The duration of the construction of the layers took 20, 30, 30 and 20 days respectively. At each stage of the construction, in addition to the stress-strain 
state and the consolidation level, the slopes stability of the structure was determined. The computation of stability was carried out using the method of strength reduction, in which the stability factor (safety) is taken as the reserve on strength of soils. The difference between the safety factor calculated by the method of strength reduction and the slopes stability factor was determined according to the methods adopted in the normative documents in the Russian Federation is described in [8].

\subsection{Option 1 - basic}

The embankment is constructed from medium size sand. There are no constructive solutions intended to strengthen the embankment base or to improve its stability. The computation model of the basic option is shown in Figure 5. The strain distribution for this shown in Figure 6. Dissipation of the pore pressure in the water-saturated soils of the base was modeled only for the stress caused by the weight of the embankment itself (permanent load). It is evident that the change in the pore pressure from the temporary moving load would not be very significant relative to the large height of the embankment, so in that instance dissipation would take much longer. Calculating the effect of the temporary load in the same way one would calculate the permanent load is extremely difficult and would lead to the wrong conclusions.

The safety factor was 1.265 at the time of the settlement at the end of consolidation (when the excess pore pressure does not exceed $1 \mathrm{kPa}$, which together with the unaccounted pore pressure arising from the temporary load, will be no more than $10 \%$ of the maximum excess pore pressure).

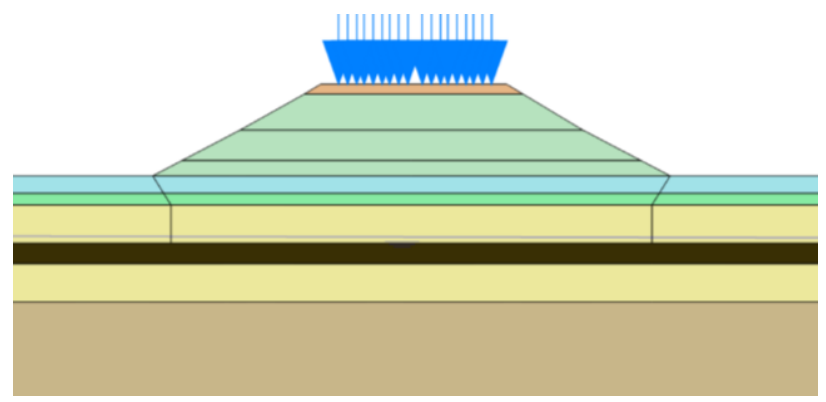

Fig. 4. Fragment of computation model for the base Option.
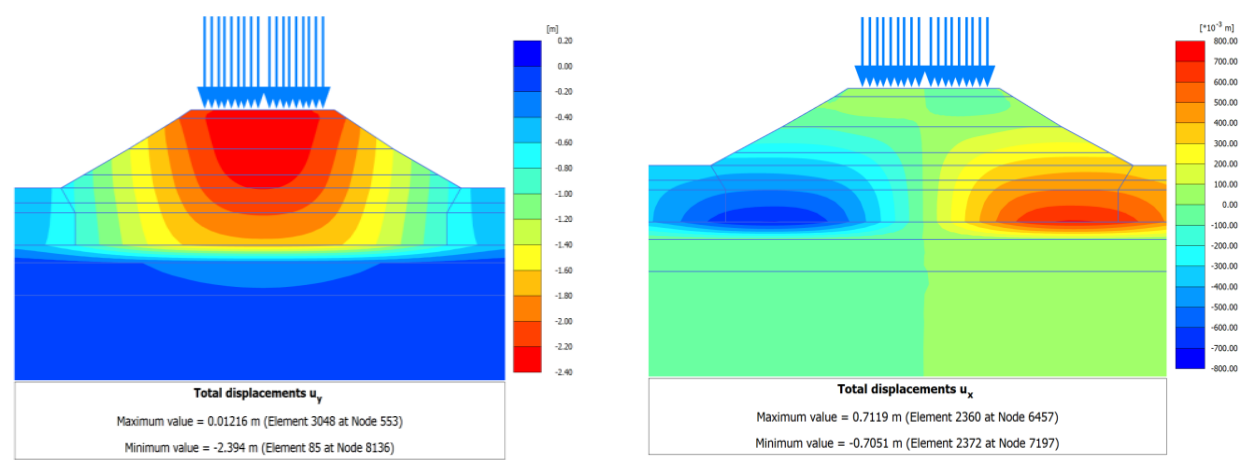

Fig. 5. Vertical and horizontal deformations of the embankment and its foundation for the base Option. 


\subsection{Option 2 - excavation of soft-plastic loam in the base of the embankment and its substitution with medium size sand}

As it can be seen from Figure 6, the substitution of soft-plastic loams made it possible to reduce the maximum vertical deformations by more than $60 \mathrm{~cm}$ and the maximum horizontal strain by $10 \mathrm{~cm}$. The safety factor changed during the consolidation period of the foundation soil from 1.15 to 1.23 .
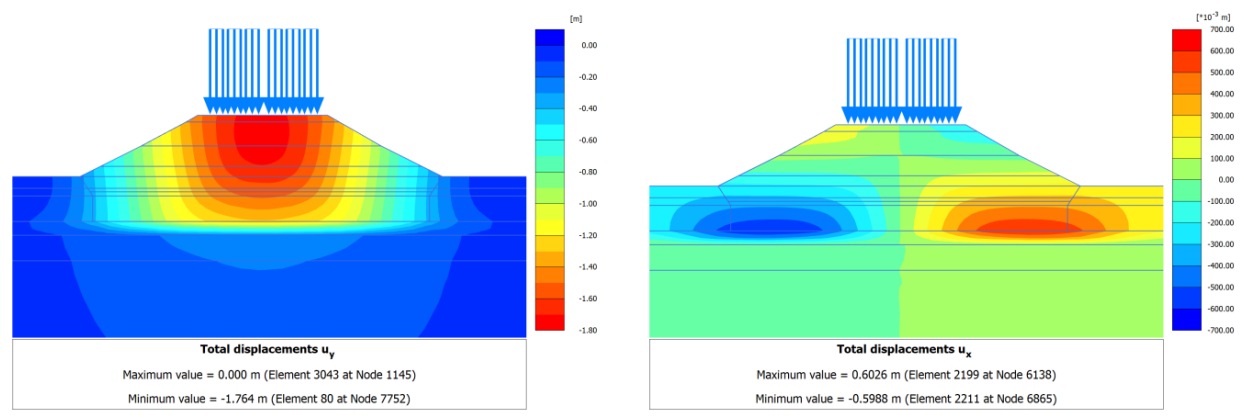

Fig. 6. Vertical and horizontal deformations of the embankment and its bases for Option 2.

\subsection{Option 3 - excavation of soft-plastic loam in the base of the embankment and its substitution with medium size sand with reinforcement of the geosynthetic material (two reinforcement schemes)}

In this Option, the influence of the geosynthetic woven material at the base of the embankment on the deformation properties of the structure and its foundation was determined. Geosynthetic material was laid into the lower layer of sand substitution. According to the first scheme, three layers of geosynthetic material were laid, on the second scheme - one layer. According to the second reinforcement scheme, the geosynthetic material is laid on the substitution soil, in the level of the surface of the base of the embankment.

It can be noted comparing the values of the maximum horizontal and vertical deformations of Option 2 (see Fig. 6) and 3 (Fig. 7), that the geosynthetic materials were practically not joining the work. Deformations decreased by a fraction of a percent.
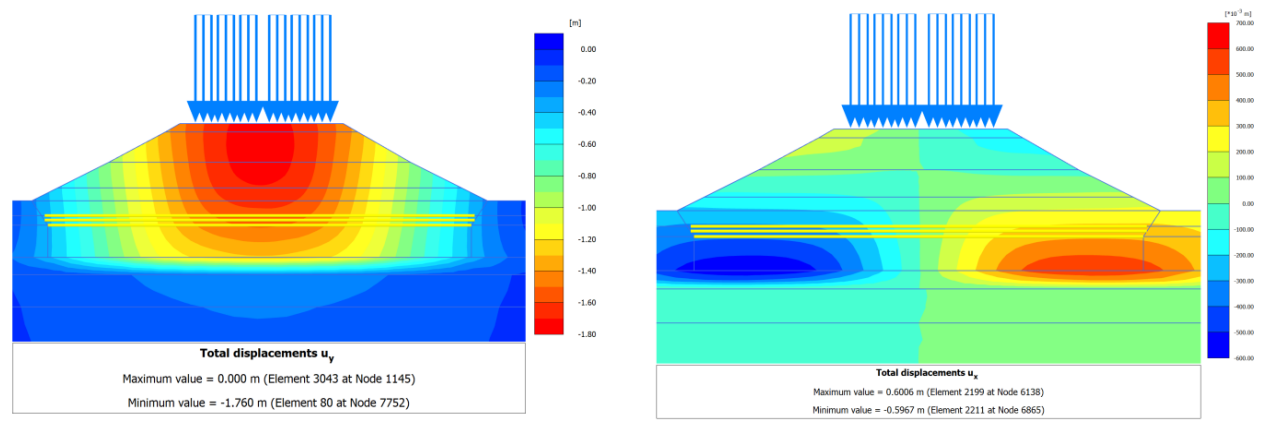

Fig. 7. Vertical and horizontal deformations of the embankment and its base for Option 3.

The computation results shown in Figure 8 show that geosynthetic materials practically don't work in both options in this particular case. This fact confirms the need to carry out 
appropriate computations every time one intends to use geosynthetic material. This will allow not only to correctly choose the material, but also to avoid its ineffective application.
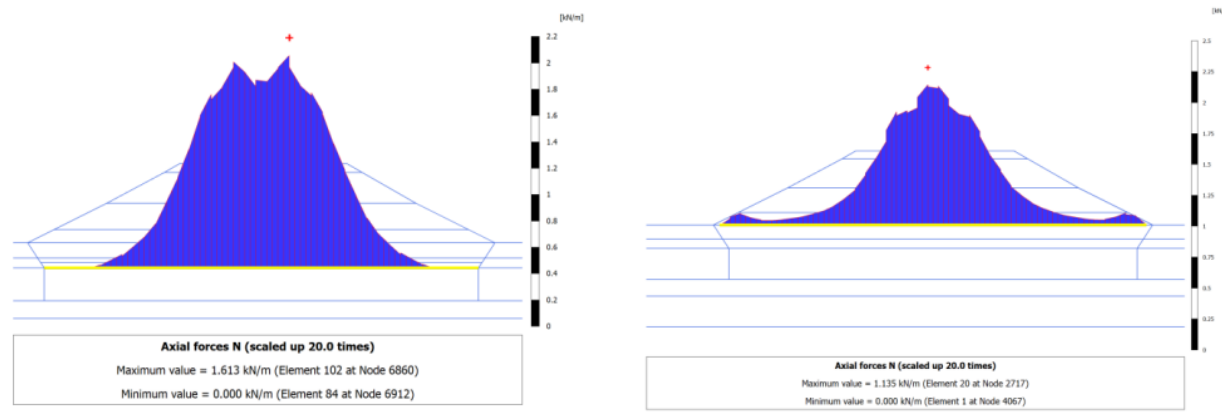

Fig. 8. The tensile forces of geosynthetic material for Option 3 for both reinforcement schemes.

\subsection{Option 4 - excavation of soft-plastic loam in the base of the embankment and its substitution with medium size sand and construction of drain piles, the bottom of which reaches the mineral bottom the buried peat}

This design of the reinforcement of the foundation allowed not only to shorten the period of consolidation of the soils in the base, but also to reduce the compressibility of the layer of buried peat reinforced with drains. Option 4 also has a geosynthetic material layer in the structure, which carries the distribution and separation functions and ensures the joint work of the sand of drains and soils of base. As can be seen from Fig. 9, the use of drain piles in combination with partial soil substitution has allowed to reduce deformations by more than two times, in comparison with the basic Option (Option 1). Axial tensile forces in geosynthetic material are not significant and do not exceed $1.4 \mathrm{kN} / \mathrm{m}$.
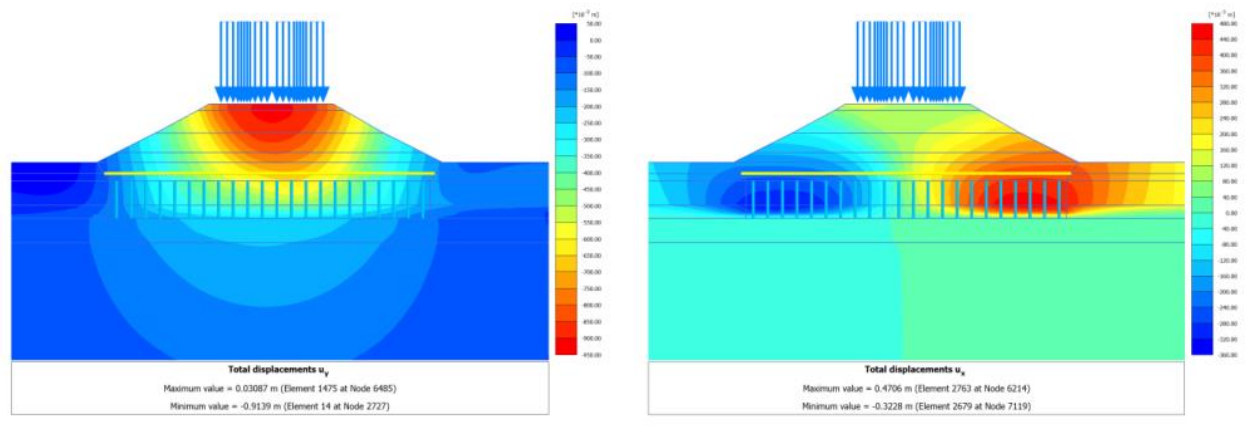

Fig. 9. Vertical and horizontal deformations of the embankment and its base reinforced with drain piles (Option 4).

\subsection{Option 5 - the base of the embankment is reinforced by a field of rectangular reinforced concrete piles $(0.4 \times 0.4 \mathrm{~m})$}

The distance between axes of the piles is $2 \mathrm{~m}$. The bearing capacity of the piles was determined at the base [9]. It is assumed that the piles will work as 'hanging'. The length of the piles is from 12 to $16 \mathrm{~m}$. A flexible grillage is added at the top of the piles. The main results of the computations for this design are shown in Figure 10. As follows from Fig. 10, the deformations of the embankment on the pile foundation are not less than for the base reinforced with drain piles. 

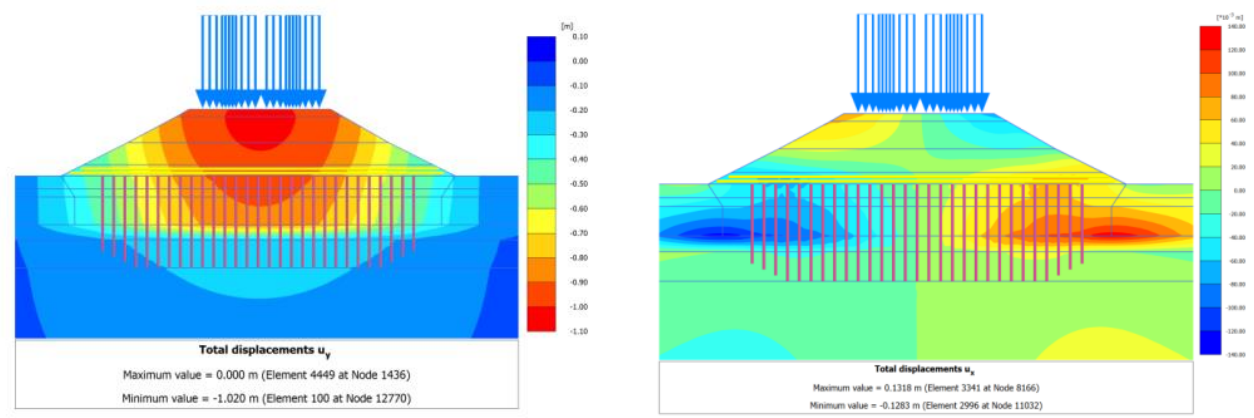

Fig. 10. Vertical and horizontal deformations of the embankment and its foundation reinforced with reinforced concrete piles (Option 5).

\subsection{The main computation results}

Table 2 shows the main results for all the Options considered.

Table 2. Results of computations for five Options.

\begin{tabular}{|c|c|c|c|c|c|}
\hline \multirow{2}{*}{ Indicators } & \multicolumn{5}{|c|}{ Options } \\
\hline & 1 & 2 & 3 & 4 & 5 \\
\hline $\begin{array}{c}\text { Maximum vertical / } \\
\text { horizontal deformation from } \\
\text { the weight of the first layer } \\
\text { of the embankment, } \mathrm{m}\end{array}$ & $\begin{array}{c}0.151 / \\
0.024\end{array}$ & $\begin{array}{l}0.126 / \\
0.017\end{array}$ & $\begin{array}{l}0.126 / \\
0.017\end{array}$ & $\begin{array}{c}0.046 / \\
0.014\end{array}$ & $\begin{array}{l}0.069 / \\
0.0123\end{array}$ \\
\hline $\begin{array}{l}\text { Maximum vertical / } \\
\text { horizontal deformation from } \\
\text { the weight of the second } \\
\text { layer of the embankment, } \mathrm{m}\end{array}$ & $\begin{array}{c}0.590 / \\
0.121\end{array}$ & $\begin{array}{l}0.553 / \\
0.120\end{array}$ & $\begin{array}{l}0.553 / \\
0.122\end{array}$ & $\begin{array}{l}0.251 / \\
0.058\end{array}$ & $\begin{array}{l}0.237 / \\
0.026\end{array}$ \\
\hline $\begin{array}{l}\text { Safety factor after the device } \\
\text { of the second layer }\end{array}$ & 1.424 & 1.421 & 1.420 & 1.405 & 1.420 \\
\hline $\begin{array}{c}\text { Maximum vertical / } \\
\text { horizontal deformation from } \\
\text { the weight of the third layer } \\
\text { of the embankment, } \mathrm{m}\end{array}$ & $\begin{array}{l}1.108 / \\
0.284\end{array}$ & $\begin{array}{l}1.115 / \\
0.326\end{array}$ & $\begin{array}{l}1.115 / \\
0.326\end{array}$ & $\begin{array}{c}0.551 / \\
0.177\end{array}$ & $\begin{array}{c}0.631 / \\
0.069\end{array}$ \\
\hline $\begin{array}{l}\text { Safety factor after the device } \\
\text { of the third layer }\end{array}$ & 1.278 & 1.272 & 1.272 & 1.262 & 1.252 \\
\hline $\begin{array}{l}\text { Maximum vertical / } \\
\text { horizontal deformation from } \\
\text { weight of pavement, } \mathrm{m}\end{array}$ & $\begin{array}{l}1.391 / \\
0.381\end{array}$ & $\begin{array}{l}1.375 / \\
0.445\end{array}$ & $\begin{array}{l}1.374 / \\
0.445\end{array}$ & $\begin{array}{l}0.666 / \\
0.239\end{array}$ & $\begin{array}{l}0.805 / \\
0.093\end{array}$ \\
\hline $\begin{array}{l}\text { Stabilized settlement of the } \\
\text { embankment, taking into } \\
\text { account the action of the } \\
\text { temporary load, } \mathrm{m}\end{array}$ & 2.394 & 1.764 & 1.760 & 0.914 & 1.020 \\
\hline $\begin{array}{l}\text { Stabilized settlement only } \\
\text { from the action of a } \\
\text { temporary load, } \mathrm{m}\end{array}$ & 0.128 & 0.072 & 0.072 & 0.146 & 0.066 \\
\hline $\begin{array}{l}\text { Safety factor immediately } \\
\text { after the completion of } \\
\text { construction }\end{array}$ & 1.262 & 1.159 & 1.215 & 1.141 & 1.225 \\
\hline $\begin{array}{c}\text { Safety factor after } \\
\text { completion of consolidation } \\
\text { soils of base }\end{array}$ & 1.265 & 1.236 & 1.353 & 1.153 & 1.239 \\
\hline
\end{tabular}

The results of the computations made it possible to choose two competitive options of strengthening the base of the embankment. These are Options 4 and 5, in which it was possible to reduce vertical and horizontal deformations by more than twice. It is important to further carry out their technical and economic comparison. 
The performed computations showed that the use of geosynthetic materials practically does not affect the values of vertical deformations (Options 3 and 5). This confirms the need to justify the effectiveness of their application to each specific case.

\section{Acknowledgment}

The authors are grateful to the organizing committee of the International Geotechnical Symposium, in particular to Prof. S.A. Kudryavtsev.

\section{References}

1. V.V. Vinogradov, A.A. Zaytsev, Physical modeling in geotechnics and in tasks of railway infrastructure, Report on EURAILTEST SNCF seminar (2018)

2. A.A. Zaytsev, 8th International Conference on Physical Modelling in Geotechnics (ICPMG), 877-881 (2014)

3. A.I. Shteyn, G.S. Pereselenkov, G.G. Orlov, A.M. Cherkasov, Proc. of the 2017 Int. Conf. Quality Management, Transport and Information Security, Information Technologies (IT\&QM\&IS-2017), 436 - 439 (2017)

4. J.P. Magnan, N. Droniuc, Y. Canepa, A. Dhouib, Proceedings of 6ISMGE, 1377-1380 (2005)

5. Russian Standard GOST R 52748-2007

6. L.T. Roman, M.N. Tsarapov, P.I. Kotov, et.al. Manual on the determination of physical and mechanical properties of freezing, frozen and thawing dispersed soils (KDU, University Book, 2018)

7. S.Ya. Lutskiy, T.V. Shepitko, A.M. Cherkasov, Sciences in Cold and Arid Regions 74, 0316-0322 (2015)

8. G.S. Pereselenkov, A.I. Shteyn, Proceedings of the TSNIIS 214, 117 - 160 (2002)

9. Russian Standard SP 24.13330.2011 